\title{
Review of: "Optimal Licensing Strategy of Green Technology With Corporate Social Responsibility (CSR)"
}

\author{
Raza Ali Tunio
}

Potential competing interests: The author(s) declared that no potential competing interests exist.

Dear Authors,

1. I'm excited to read this paper. In this research, duopoly model is considered. The authors investigated the firm's green technology licensing strategy with CSR and analyze the effects of CSR behaviours on environment and social welfare.

2. It is also necessary to add some academic literature of the last year 2020-21.

3. Must read and cite these research articles in your article it will be helpful to readers. https://doi.org/10.1007/s11356020-11247-4, https://doi.org/10.1007/s11356-021-14872-9).

4. In short, this article combines theoretical and equation analysis with empirical research, with clear themes, clear thinking, and structure.

5. After implications of my suggestions and recommendations your article is accepted.

Wish you good luck 